\title{
A Multidimensional Framework for Financial-Economic Decisions
}

\author{
Winfried Hallerbach \& Jaap Spronk
}

\begin{tabular}{|l|l|}
\hline \multicolumn{2}{|l|}{ ERIM REPORT SERIES RESEARCH IN MANAGEMENT } \\
\hline ERIM Report Series reference number & ERS-2003-021-F\&A \\
\hline Publication status / version & March 2003 \\
\hline Number of pages & 23 \\
\hline Email address corresponding author & spronk@few.eur.nl \\
\hline Address & Erasmus Research Institute of Management (ERIM) \\
& Rotterdam School of Management / Faculteit Bedrijfskunde \\
& Rotterdam School of Economics / Faculteit Economische \\
& Wetenschappen \\
& Erasmus Universiteit Rotterdam \\
& PoBox 1738 \\
& 3000 DR Rotterdam, The Netherlands \\
& Phone: \# 31-(0) 10-408 1182 \\
& Fax: \# 31-(0) 10-408 9640 \\
& Email: info@erim.eur.nl \\
& Internet: www.erim.eur.nl \\
\hline
\end{tabular}

Bibliographic data and classifications of all the ERIM reports are also available on the ERIM website: www.erim.eur.nl 


\title{
ERASMUS RESEARCH INSTITUTE OF MANAGEMENT
}

\author{
REPORT SERIES
}

RESEARCH IN MANAGEMENT

\begin{tabular}{|c|c|c|}
\hline \multicolumn{3}{|c|}{ BIBLIOGRAPHIC DATA AND CLASSIFICATIONS } \\
\hline Abstract & \multicolumn{2}{|c|}{$\begin{array}{l}\text { Most financial-economic decisions are made consciously, with a clear and constant drive to } \\
\text { 'good', 'better' or even 'optimal' decisions. Nevertheless, many decisions in practice do not earn } \\
\text { these qualifications, despite the availability of financial economic theory, decision sciences and } \\
\text { ample resources. We plea for the development of a multidimensional framework to support } \\
\text { financial economic decision processes. Our aim is to achieve a better integration of available } \\
\text { theory and decision technologies. We sketch (a) what the framework should look like, (b) what } \\
\text { elements of the framework already exist and which not, and (c) how the MCDA community can } \\
\text { co-operate in its development. }\end{array}$} \\
\hline \multirow{5}{*}{$\begin{array}{l}\text { Library of Congress } \\
\text { Classification } \\
\text { (LCC) }\end{array}$} & $5001-6182$ & Business \\
\hline & $5601-5689$ & Accountancy, Bookkeeping \\
\hline & 4001-4280.7 & Finance Management, Business Finance, Corporation Finance \\
\hline & HG 4000+ & Financial Management \\
\hline & HD 30.22 & Decision making \\
\hline \multirow{5}{*}{$\begin{array}{l}\text { Journal of Economic } \\
\text { Literature } \\
\text { (JEL) }\end{array}$} & M & Business Administration and Business Economics \\
\hline & M 41 & Accounting \\
\hline & G 3 & Corporate Finance and Governance \\
\hline & G 30 & Corporate Finance \\
\hline & C 44 & Decision Theory \\
\hline \multirow{4}{*}{$\begin{array}{l}\text { European Business Schools } \\
\text { Library Group } \\
\text { (EBSLG) }\end{array}$} & $85 \mathrm{~A}$ & Business General \\
\hline & $225 \mathrm{~A}$ & Accounting General \\
\hline & $220 \mathrm{~A}$ & Financial Management \\
\hline & $220 \mathrm{~A}$ & Financial Management \\
\hline \multicolumn{3}{|c|}{ Gemeenschappelijke Onderwerpsontsluiting (GOO) } \\
\hline \multirow[t]{4}{*}{ Classification GOO } & 85.00 & Bedrijfskunde, Organisatiekunde: algemeen \\
\hline & 85.25 & Accounting \\
\hline & 85.30 & Financieel management, financiering \\
\hline & 85.30 & Financieel management, financiering \\
\hline \multirow[t]{3}{*}{ Keywords GOO } & \multicolumn{2}{|c|}{ Bedrijfskunde / Bedrijfseconomie } \\
\hline & \multicolumn{2}{|c|}{ Accountancy, financieel management, bedrijfsfinanciering, besliskunde } \\
\hline & \multicolumn{2}{|c|}{ Bedrijfsfinanciering, Besliskunde } \\
\hline Free keywords & \multicolumn{2}{|c|}{ Finance; Financial Decisions; Multiple criteria; Decision Making; Decision Analysis } \\
\hline
\end{tabular}




\title{
A Multidimensional Framework for Financial-Economic Decisions
}

\author{
Winfried Hallerbach \& Jaap Spronk ${ }^{1}$
}

(this version) March 3, 2003

\begin{abstract}
Most financial-economic decisions are made consciously, with a clear and constant drive to 'good', 'better' or even 'optimal' decisions. Nevertheless, many decisions in practice do not earn these qualifications, despite the availability of financial economic theory, decision sciences and ample resources. We plea for the development of a multidimensional framework to support financial economic decision processes. Our aim is to achieve a better integration of available theory and decision technologies. We sketch (a) what the framework should look like, (b) what elements of the framework already exist and which not, and (c) how the MCDA community can co-operate in its development.
\end{abstract}

\footnotetext{
${ }^{1}$ Both Erasmus University Rotterdam, the Netherlands. Homepages and contact information can be found on www.finance-on-eur.nl under the heading 'staff'.
} 


\section{Introduction}

Financial-economic decision problems do come in a great variety. Individuals are involved in decisions concerning their future pensions, financing of their houses and consumer goods and investments in mutual funds. Firms, financial institutions and advisors are involved in cross-country mergers, complicated swap contracts and mortgage-backed securities, to name just a few examples.

Despite this variety, these decisions have a lot in common. It is maybe "money" that first comes to mind here. But as shown before, there are many reasons to treat financial-economic problems as multiple criteria decision problems: because of multiple actors, multiple policy constraints and multiple sources of risk (see e.g. Spronk \& Hallerbach [1997] and Hallerbach \& Spronk [2000, 2002], Martel \& Zopounides [1998], Zopounides [1999], and Steuer \& Na [2002]). Two other common elements in financial decisions are that their outcomes are distributed over time and uncertain and thus involve risk. Another common factor is that most decisions are made consciously, with a clear and constant drive to make "good", "better" or even "optimal" decisions. In this drive to improve on financial decisions, we stumble across an area of tension between decision making in practice on the one hand and the potential contributions of finance theory and decision tools on the other. Although the bulk of finance theory is of a descriptive nature, thus focusing on the "average" or "representative" decision maker, we observe a large willingness to apply financial theory in actual decision making. At the same time the knowledge about decision tools that can be applied in the specific decision situation at hand, is limited. Clearly there is need of a framework that can provide guidance in applying financial theory, decision tools, and common sense, to solving financial problems.

In this paper we sketch a multi-dimensional framework that can support the financial-economic decision making process. Section 2 provides a detailed discussion of financial decision problems and financial theory. We outline financial decision areas and summarize financial concepts and principles. In Section 3, we confront descriptive modelling with conditional normative modelling and explain the success of financial modelling in the preference-free context of derivative securities. Section 4 is devoted to financial decision problems and decision sciences. In Section 5 we merge the insights into a set of principles that together constitute the pillars of a framework for solving financial decision problems in practice. Section 5 describes why and Section 6 shows how financial decision alternatives can be described as multi-dimensional profiles -thus getting access to multicriteria decision analysiswhile benefiting from the way modern finance looks at dynamic decisions. Our conclusions are summarized in Section 7.

\section{Financial decision problems and financial theory}

Sections 2 and 3 discuss the link between financial theory, financial modelling, and making financial decisions. In this section we outline financial decision areas and discuss the financial key issues of valuation, risk management and performance evaluation. This brings us to a discussion of the focus of modern finance. This serves as a preamble for section 3 where we evaluate the potential contribution of contemporary financial modelling to applied financial decision-making. 


\section{Finance: issues, concepts and principles}

"Finance is a sub field of economics distinguished by both its focus and its methodology. The primary focus of finance is the workings of the capital markets and the supply and the pricing of capital assets. The methodology of finance is the use of close substitutes to price financial contracts and instruments. This methodology is applied to value instruments whose characteristics extend across time and whose payoffs depend upon the resolution of uncertainty." (Ross [1989, p.1])

The field of finance is concerned with decisions with respect to the efficient allocation of scarce capital resources over competing alternatives. The allocation is efficient when the alternative with the highest value is chosen. Current value is viewed as the (present) value of claims on future cash flows. Hence we can say that financial decisions involve the evaluation and valuation of future - and hence uncertain or "risky" - cash flow streams. Valuation is done by comparing the cash flow stream X that has to be valued with cash flow streams $\{\mathrm{A}, \ldots, \mathrm{Z}\}$ that are traded on financial markets. When a traded cash flow stream $\mathrm{Y}$ has been identified that is a perfect ("close") substitute of X, then their value must be the same. After all, when introducing $\mathrm{X}$ to the market it cannot be distinguished from Y. Accepting the efficient market hypothesis (stipulating that all available information is fully and immediately incorporated in market prices), then the market price of $\mathrm{Y}$ equals the value of $\mathrm{Y}$ - and hence the value of $X$. This explains the crucial role of financial markets.

The valuation of future cash flow streams is a key issue in finance. The process of valuation must be preceded by evaluation: without analysing the characteristics of a cash flow stream, no potential substitute can be identified. Since it is uncertain what the future will bring, the analysis of the risk characteristics will be predominant. Moreover, when time passes by, the current value must be guarded and protected against influences that may corrode this value. This in turn implies the need for risk management.

There are basically three areas of financial decisions:

1. Capital budgeting: to what portfolio of real investment projects should a firm commit its capital? The central issues here are how to evaluate investment opportunities, how to distinguish profitable from non-profitable projects and how to choose between competing projects.

2. Corporate financing: this encompasses the capital structure policy and dividend policy and addresses questions as: how should the firm finance its activities? What securities should the firm issue or what financial contracts should the firm engage in? What part of the firm's earnings should be paid as cash dividends and what part reinvested in the firm? How should the firm's solvency and liquidity be maintained?

3. Financial investment: this is the mirror image of the previous decision area and involves choosing a portfolio of financial securities with the objective to change the consumption pattern over time.

In each of these decision areas the financial key issues of valuation, risk analysis and risk management, and performance evaluation can be recognized. From the discussion above several financial concepts emerge: financial markets, efficient allocation and 
market value. In approaching the financial decision areas, some financial principles or maxims are formulated. The first is self-interested behaviour: economic subjects are driven by non-satiation ("greed"). This ensures the goal of value maximization. Prices are formed on financial markets and under the efficient market hypothesis the prices of securities coincide with their value. Value has time and risk dimensions. With regard to the former time preference is assumed, which reflects the positive time value of money (a dollar today is preferred to a dollar tomorrow). With respect to the latter risk aversion is assumed (a safe dollar is preferred to a risky dollar). Overall risk may be reduced by diversification: combining risky assets or cash flow streams may be beneficial. In one way or another, the trade-off between expected return and risk that is imposed by market participants on the evaluation of risky ventures will translate into a risk-return trade-off that is offered by investment opportunities in the market.

Since value has time and risk aspects the question arises what mechanisms can be invoked to incorporate these dimensions in the valuation process. There are basically two mechanisms. The first is the arbitrage mechanism. Value is derived from the presumption that there do not exist arbitrage opportunities. This no-arbitrage condition excludes sure profits at no cost and implies that perfect substitutes have the same value. This is the law of one price, one of the very few laws in financial economics. It is a strong mechanism, requiring very few assumptions on market subjects, only non-satiation. Examples of valuation models built on no-arbitrage are the Arbitrage Pricing Theory for primary financial assets and the Option Pricing Theory for derivative securities. The second is the equilibrium mechanism. In this case value is derived from the market clearing condition that demand equals supply. The latter mechanism is much weaker than the former: the exclusion of arbitrage opportunities is a necessary but by no means a sufficient condition for market equilibrium. In addition to non-satiation also assumptions must be made regarding the risk attitudes of all market participants. Examples of equilibrium-based models are the Capital Asset Pricing Model and its variants. Below we discuss the differences between the two valuation approaches in more detail. It suffices to remark that it is still a big step from the principles to solving actual decision problems.

\section{The focus of finance research}

An alternative - albeit almost circular - definition of finance is provided by Jarrow [1988, p.1]:
"Finance theory (...) includes those models most often associated with financial economics. (...) [A] practical definition of financial economics is found in those topics that appear with some regularity in such publications as Journal of Finance, Journal of Financial and Quantitative Analysis, Journal of Financial Economics, and Journal of Banking and Finance."

Browsing through the back volumes of these journals and comparing them to the more recent issues reveals a blatant development in nature and focus. In the dawn of finance as a separate field in science the papers were descriptive in a narrative way and in mainly a restrictive focus on financial instruments and institutions. Finance as a decision science emerged in the early 1950s, when Markowitz [1950, 1952] studied the portfolio selection decision and launched what now is known as Modern Portfolio Theory. In the 1960s and the early 1970s, many financial economic decision problems 
were approached by operational research techniques; see for example Ashford, Berry \& Dyson [1988] and McInnes \& Carleton [1982] for an overview. Consequently, this type of research became more and more absorbed by the OR community and their journals.

But what direction did finance take? Over the last 25 years mathematical models have replaced the verbal models and finance has founded itself firmly in a neo-classical micro-economic tradition. Over this period we observe a shift to research that is descriptive in a sophisticated econometrical way and that focuses on the statistical characteristics of (mainly well-developed) financial markets where a host of financial instruments is traded. Bollerslev [2001, p.41] aptly describes this shift as follows:

"A cursory look at the traditional econometrics journals (...) severely underestimates the scope of the field [of financial econometrics], as many of the important econometric advances are now also published in the premier finance journals - the Journal of Finance, the Journal of Financial Economics, and the Review of Financial Studies - as well as a host of other empirically oriented finance journals."

The host of reported research addresses the behaviour of financial market prices. The study of the pricing of primary securities is interesting for its own right, but it is also relevant for the pricing of derivative securities. Indeed, the description of the pricing of primary assets and the development of tools for pricing derivative assets mark the success story of modern finance.

The body of descriptive finance theory has grown enormously. According to modern definitions of the field of finance, the descriptive nature is even predominant:

"The core of finance theory is the study of the behaviour of economic agents in allocating and deploying their resources, both spatially and across time, in an uncertain environment." (Merton [1995, p.7])

Compared to Ross' [1989] definition cited earlier, the focus is purely positive. The question arises to what extent the insights gained from descriptive finance - how sophisticated they may be from a mathematical, statistical or econometric point of view - can serve as guidelines for financial decisions in practice. Almost 30 years ago, in the preface of their book "The Theory of Finance", Eugene Fama and Merton Miller defended their omission of detailed examples, purporting to show how to apply the theory to real-world decision problems, as:

"(...) a reflection of our belief that the potential contribution of the theory of finance to the decision-making process, although substantial, is still essentially indirect. The theory can often help expose the inconsistencies in existing procedures; it can help keep the really critical questions from getting lost in the inevitable maze of technical detail; and it can help prevent the too easy, unthinking acceptance of either the old clichés or new fads. But the theory of finance has not yet been brought, and perhaps never will be, to the cookbook stage." (Fama \& Miller [1972, p.viii]) 
Careful inspection of current finance texts reveals that in this respect not much has changed. However, pure finance theory and foolproof financial recipes are two extremes of a continuum. The latter cookbook stage will never be achieved, of course, and in all realism and wisdom this alchemic goal should not be seeked for. But what we dearly miss is an extensive body of research that bridges the apparent gap between these two extremes, research that shows how to solve real-world financial decision problems without violating insights offered by pure finance theory on the one hand and without neglecting the peculiarities of the specific decision problem on the other. To elaborate further on this point it is necessary to draw the distinction between positive modelling and conditional-normative modelling, and to discuss the crucial difference in the role of assumptions in both types of modelling. This is done in section 3 .

\section{Modelling financial decision problems}

By definition, modelling involves making assumptions. The role of assumptions is to simplify the real world in order to make it tractable. In this respect the art of modelling is to make assumptions there where they most contribute to the model's tractability but at the same time least hurt the realism of the model. But the considerations in this trade-off are fundamentally different for positive models on the one hand and conditional-normative models on the other.

\section{Descriptive vs. conditional-normative modelling}

In a positive or descriptive model simplified assumptions are made in order to obtain a testable implication of the model. The validity of the model is evaluated according to the inability to reject the model's implications at some preset level of significance. So validity is of an empirical nature, solely judged by the implications of the model. Consider the example of an equilibrium asset-pricing model. As a starting point assumptions are made with respect to the preferences of an imaginary investor and the risk-return characteristics of the investment opportunities. These assumptions are sufficiently strong to allow solving the portfolio optimisation problem. Next a homogeneity condition is imposed: all investors in the market possess the same information and share the same expectations. This allows focusing on "the representative investor". Finally the equilibrium market clearing condition is imposed: all available assets (supply) must be incorporated in the investment portfolio of this representative investor (demand). The first order conditions of portfolio optimality then stipulate the trade-off between risk and expected return that is required by the investor. Because of the market clearing the assets do offer the same trade-off. Hence a market-wide relationship between risk and return is established and this relationship is the object of empirical testing. As long as the pricing relationship is not falsified the model is accepted, irrespective whether the necessary assumptions are realistic or not. When the model is falsified, deduction may help to amend the assumptions where after the same procedure is followed. This hypothetic-deductive cycle ends when the model is no longer falsified by the empirical data at hand.

In a conditional-normative model also simplified assumptions are made in order to obtain a tractable model. These assumptions relate to the preferences of the decision maker and to the representation of the set of choice alternatives. The object of the conditional-normative modelling is not to infer a testable implication but to obtain a decision rule. This derived decision rule is valid and can normatively be 
applied conditional on the fact that the decision maker satisfies the underlying assumptions; cf. Keynes [1891].

In order to support decisions in finance, obviously both the preferences of the decision maker and the characteristics of the choice alternatives should be adequately understood and related to each other. Unfortunately, the host of financial-economic modelling is of a positive nature and focuses on the 'average' decision maker instead of addressing the particular (typically non-average) decision maker. The assumptions underlying financial theory at best describe 'average individuals' and 'average decision situations' and hence are not suited to describe specific individual decision problems. The assumptions made to simplify the decision situation often completely redefine the particular problem at hand. The real world is replaced by an oversimplified model-world. As a consequence not the initial problem is solved but a synthesized and redefined problem that is not even recognized by the decision maker himself. The over-simplified model becomes a Procrustes bed for the financial decision maker who seeks advice.

For example it is assumed that the decision maker has complete information and uncertainty is moulded in the form of easily tractable probability distributions. Even worse, positive knowledge and descriptive theories that by definition reflect the outcomes of decisions made by some "representative" decision maker are used to prescribe what actions to take in a specific decision situation. For example, equilibrium asset pricing theories predict the effects of the decisions and actions of many individuals on the formation of prices in financial markets. Under the homogeneity condition the collective of these investors is reduced to the representative investor. When the pricing implications of the model are simply used to guide actual investment behaviour, then the decision maker is forced into the straitjacket of this representative investor.

Unfortunately we observe that conditional-normative financial modelling is only regarded as starting point for descriptive modelling and not pursued as being relevant for its own sake. After almost twenty years, Hastie's [1982] lament has not lost much of its truth:

"In American business today, particularly in the field of finance, what is needed are approximate answers to the precise problem rather than precise answers to the approximate problem."

\section{A success story of financial modelling}

Apart from the positive modelling of financial markets as described above, there is one other field in finance in which the achievements of applied modelling are apparent: Option Pricing Theory, the set of models that enable the pricing of derivative securities and all kind of contingent claims. Indeed and without doubt, the option pricing formulas developed by Black \& Scholes [1973] and Merton [1973] mark a huge success in the history of financial modelling. Contingent claims analysis made a flying start, and:

“.... when judged by its ability to explain the empirical data, option pricing theory is the most successful theory not only in finance, but in all of economics." (Ross [1989, p.24]) 
"Given a theory that works so well, the best empirical work will be to use it as a tool rather than to test it." (Ross [1989, p.23])

Indeed, modern day derivatives trading would be unthinkable without the decision support of an impressive coherent toolbox for analysing the risk characteristics of derivatives and for pricing them in a consistent way. Compared to this framework, the models and theories developed and tested for primary assets even look pale. What is the reason for the success of derivatives research?

For an explanation we turn to the principal tool used in option pricing theory: no-arbitrage valuation. By definition derivative securities derive their value from primary underlying assets. Under some mild assumptions a dynamic trading strategy can be designed in which the derivative security is exactly replicated with a portfolio of the primary security and risk free bonds. Under the no-arbitrage condition the current value of the derivative security and the replicating portfolio should be identical. Looking from another perspective, a suitably chosen hedge combination of the derivative and the underlying security produces a risk free position. On this position the risk free rate must be earned, otherwise there exist arbitrage opportunities. Since the position is risk free, risk attitudes and risk aversion do not enter the story. Therefore a derivative security will have the same value in a market environment with risk neutral investors as in a market with risk averse investors. This in turn implies that a derivative can be priced under the assumption that investors are risk neutral. As a consequence no assumptions are required on preferences (other than non-satiation), utility functions, the degree of risk aversion and risk premia. Thus option-pricing theory can escape from the burden of modelling of preference structures. Instead, research attention shifts to analysing price dynamics on financial markets. An additional reason for the success in derivatives research is that the analytical and mathematical techniques are similar to those used in the physical sciences (see for example Derman [1996a]). From the seminal papers on, researchers have benefited from the techniques developed by and results obtained by theoretical physicists.

Of course, even for derivatives modelling some assumptions are required. This introduces model risk. When the functional relationships stipulated in the model are wrong, or when relevant input parameters of the model are incorrectly estimated, the model produces the wrong value and the wrong risk profile of the derivative. To an increasing degree financial institutions are aware that great losses can be incurred because of model risk. Especially in risk management and derivatives trading model risk is a hot item (see Derman [1996b]). This spurred Robert Merton to ventilate this warning:

"At times, the mathematics of the models become too interesting and we lose sight of the models' ultimate purpose. The mathematics of the models is precise, but the models are not, being only approximations to the complex, real world. Their accuracy as a useful approximation to that world varies considerably across time and place. The practitioner should therefore apply the models only tentatively, assessing their limitations carefully in each application." (Merton [1995, p.14])

Ironically this quote was taken just after the very successful launch of Long Term Capital Management (LTCM), the hedge fund of which Merton and Myron Scholes 
were the founding partners. In 1998, LTCM collapsed and model risk played a very important role in this debacle.

Summarizing we draw the conclusion that successful applied financial modelling does exist, and blossoms in the field of derivatives. Here also the validity of the assumptions is crucial, this in contrast to positive modelling. However, in the field of derivatives with replicating strategies and arbitrage-based valuation, the concept of "absence of risk" is well defined and no preference assumptions are needed in the modelling process. For modelling decisions regarding the underlying primary assets, in contrast, assumptions on the decision maker's preferences and on the "risk" attached to the outcomes of the choice alternatives are indispensable. For these types of financial problems, the host of simplifying assumptions that are made in the descriptive modelling framework invalidate the use of the model in a specific decision situation. Thus we face the following challenge: how can we retain the conceptual foundation of the financial-economic framework and still provide sound advice that can be applied in multifarious practice? We will further explore this issue in section 5 . But first we sketch the relationship between decision sciences and financial decision making.

\section{Financial Decision Problems and Decision Sciences}

Over the last fifty years or so, the financial discipline has shown continuously rapid and profound changes, both in theory and in practice. Many disciplines have been affected by internationalisation (globalisation), deregulation, privatisations, computerization and communication technologies. Hardly any field has been influenced as much as finance. After the mainly institutional and even somewhat ad hoc approaches before the fifties, Markowitz [1950,1952] has opened new avenues by formalizing and quantifying the concept of 'risk'. In the decades that followed, a lot of attention was paid to the functioning of financial markets and the pricing of financial assets including options. The year 1973 gave birth to the first official market in options (CBOE) and to crucial option pricing formulas that have become famous quite fast (Black-Scholes and Cox-Ross-Rubinstein, see Hull [2003]), both in theory and practice. At that time, financial decision problems were structured by a) listing a number of mutually exclusive decision alternatives, b) describing them by their (estimated) future cash flows, including an estimation of their stochastic variation and later on including the effect of optional decisions and c) valuing them by using the market models describing financial markets.

In the seventies, eighties and nineties, the financial world saw an enormous growth in derivative products, both in terms of variety and in terms of market volumes.

Financial institutions have learnt to work with complex financial products. Academia has contributed by developing many pricing models, notably for derivatives. Also, one can say that financial theory has been rewritten in the light of contingent claims ('optional decisions') and will soon be further reshaped by giving more attention to game elements in financial decisions. The rapid development of the use of complex financial products has certainly not been without accidents. This has led regulators to demand for more precise (e-)valuation and reporting of financial positions (cf. e.g. the emergence of the Value-at-Risk concept, see Jorion [2001]). 
In addition to the analysis of financial risk also the structured management of financial risk has come to the frontline. In their textbook, Bodie \& Merton [2000] describe the threefold task of the financial discipline as Valuation, Risk Management and Optimization. We like to slightly amend the latter threefold task of financial management as Valuation, Risk Management and Decision-Making. The reason is that financial decision problems often have to be solved in dynamic environments where information is not always complete, different stakeholders with possibly conflicting goals and constraints play a role and clear-cut optimisation problems cannot always be obtained (and solved).

At the same time, many efforts from the decision-making disciplines are misdirected. For instance, some approaches fail to give room for the inherent complexity of the decision procedure given the decision maker's specific context. Other approaches concentrate on the beauties of a particular multiple criteria decision method, without doing full justice to the peculiarities of the decision context. Aside from being partial in this respect, useful principles and insights offered by financial economic theory are often not integrated in the decision modelling. It is therefore no surprise that one can observe in practice unstructured ad hoc approaches as well as complex approaches that severely restrict the decision process.

\section{A framework for solving financial decision problems}

In our view it is the role of financial modelling to support financial decision making, taking account of the peculiarities of the precise problem, where possible taking benefit from the results of financial theory. In our framework we therefore strive to bridge the gap between decision-making disciplines, the financial economic discipline and the need for adequate decision support in this field.

\section{Principles}

This framework is built on the principle that assumptions should be made where they help the modelling process the most and hurt the particular decision problem the least. $^{2}$ We call this the Principle of Low Fat Modelling. When (supporting in) solving a decision, make use of all available information, but do not make unrealistic assumptions with respect to the availability of information. Do not make unrealistic assumptions that disqualify the specific decision context at hand. There should be ample room to incorporate idiosyncrasies of the decision context within the problem formulation, thus recognizing that the actual (non-average) decision maker is often very different from the "representative" decision maker. The preferences of the decision maker may not be explicitly available - and may even not be known in detail by the decision maker himself. The uncertainty he faces with respect to the potential outcomes of his decisions may not be readily represented by means of some tractable statistical distribution. In many real-life cases uncertainty can only be described in imprecise terms and is the available information far from complete. And when the preferences of the decision maker are confronted with the characteristics of the decision alternatives, the conditional-normative nature of derived decision rules and advice should be accepted.

\footnotetext{
${ }^{2}$ The underlying assumptions must be validated and the effectiveness and efficiency of the actions taken must be evaluated systematically. The latter calls for a sophisticated performance evaluation process that explicitly acknowledges the role of learning.
} 
The second principle underlying our framework is the Principle of Eclecticism. One should borrow all the concepts and insights from modern financial theory that help to make better financial decisions. Financial theory can provide rich descriptions of uncertainty and risk. Examples are the multi-factor representation of risk in which the risk attached to the choice alternatives is conditioned on underlying factors; the contingent claims approach in which the decision outcomes are conditioned on the opportunity to adjust or revise decisions in the future; and game theory in which the outcomes are also conditioned on potential (conflicting) decisions made by other parties. But it is not the availability of theoretical insights that determines their application; it depends on the specific decision context at hand.

By concentrating on specific problem characteristics, there is obviously more 'to be seen' but at the same time it is possible to make observation errors and, maybe more worrisome: the problem and its context may be changing over time. This calls for the Principle of Permanent Learning, which stresses the process nature of decision making in which both the representation of the problem and the problem itself can change over time. Therefore, there is a permanent need to critically evaluate the problem formulation, the decisions made and their performance. Obviously, decisionmaking and performance evaluation are two key elements in the decision making process. As argued in Spronk and Vermeulen [2003], performance evaluation of decisions should be structured such that the original idiosyncrasies of the problem (i.e. at the time the decision was made) are fully taken into account at the moment of evaluation, (i.e. ex post). By doing so, one increases the chance of learning from errors and misspecifications in the past.

\section{Allocative decisions}

Financial decisions are allocative decisions, in which both time and uncertainty (and thus risk) play a crucial role. In order to support decisions in finance, both the preferences of the decision maker and the characteristics of the choice alternatives should be adequately understood and related to each other.A distinction can be made between 'pure' financial decisions in which cash flows and economic (market) value steer the decision and 'mixed' financial decisions in which also other criteria are considered. In financial theory, financial decisions are considered to be pure. In practice, most decisions are mixed. Hallerbach \& Spronk [2002] show that many financial decisions are mixed and thus should be treated as multiple criteria decision problems.

The solution of pure financial decisions requires the analysis, valuation and management of risky cash flow streams and risky assets. The solution of mixed financial problems requires, in addition, the analysis of other effects of the decision to be made. Effects that are, like the cash flows, uncertain and distributed over time. This implies that, in order to describe the effects of mixed decisions, multidimensional impact profiles should be used (cf. Spronk \& Hallerbach [1997]). The use of multi-dimensional impact profiles naturally opens the door to multicriteria decision analysis.

Another distinction is between the financial decisions of individuals and those of companies and other institutions. The reason for this distinction is in the different way of steering decisions. Individual decisions are guided by individual preferences (e.g. as described by utility functions), while decisions of institutions such as firms are often guided by some aggregate objective (e.g. market value maximization in the pure financial problems of financial theory). 


\section{Uncertainty and risk}

In each of the types of financial decisions just described, the effects are distributed over future time periods and uncertain. In order to evaluate these possible effects, available information should be used to develop a 'picture' of these effects and their likelihood. In some settings there is complete information but more often information is incomplete. In our framework we use multi-dimensional risk profiles for modelling uncertainty and risk. This is another reason why multicriteria decision analysis is opportune when solving financial decision problems. We will discuss these profiles in more detail in section 6 .

\section{A bird eye's view of the framework}

In Figure 1, a bird eye's view of the framework is presented. The framework integrates several elements in a process-oriented approach towards financial decisions. The left side of Figure 1 represents the elements that lead to decisions, represented by the Resolution/Conclusion box at the lower left hand side. As mentioned above, performance evaluation (shown at the lower right hand side of the figure) is an integral part of the decision-making process. However, in this article we do not pay further attention to performance evaluation or to the feedback leading from performance evaluation to other elements of the decision-making process.

Financial decision problems will often be put as allocative problems. At this stage, it is important to determine whether the problem is a mixed or pure financial problem. Also, one should know who decides and which objectives are to be served by the decisions.

In the next step, the problem will be defined more precisely. Many factors play a role here. For instance, the degree of upfront structure in the problem definition, the similarity with other problems, time and commitment from the decision maker(s), availability of time, similarity to problems known in theory and so on. In this stage, the insights from financial theory often have to be supplemented (or even amended) by insights from other disciplines and by the discipline of common sense. The problem formulation can thus be seen as a theoretical description (we use the label 'local theory') of the problem.

After the problem formulation, data have to be collected, evaluated and sometimes transformed into estimates. These data are then used as inputs for the formalization of the problem description. The structure of the problem, together with the quality and availability of the data determines what tools can be used and in which way. As explained above, the use of multi-dimensional impact profiles does almost naturally lead to the use of multicriteria decision analysis. 


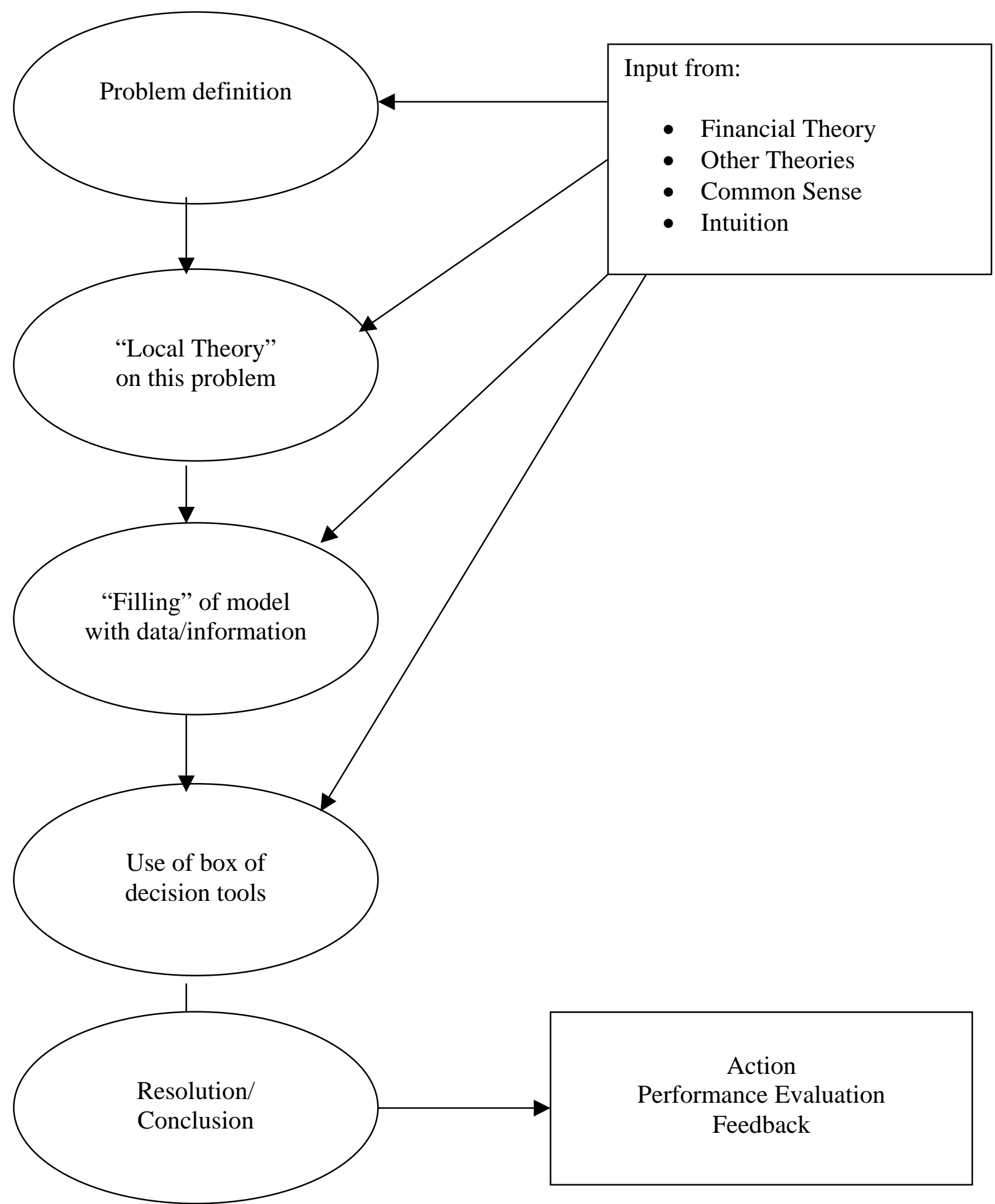

Figure 1: A Bird Eye's View of the Framework 


\section{The framework and modern financial theory}

In our framework we try to borrow all concepts and insights from modern financial theory that help to make better financial decisions. As will be shown in more detail in Section 6, financial theory provides rich and powerful tools for describing uncertainty and risk. Examples are the multi-factor representation of risk, which leads to multidimensional impact profiles that can be integrated within multicriteria decision analysis. A very important contribution of financial theory is the contingent claims approach in which the decision outcomes are conditioned on the opportunity to adjust or revise decisions in the future. This comes together with financial markets where contingent claims are being traded at enormous volumes. This brings us at the role of financial markets as instruments to trade risks, to redistribute risks and even to eliminate some risks. We believe and hope that contingent claims thinking will also be used in other domains than finance. In the first place because of what it adds when describing decision problems. Secondly, new markets may emerge in which also nonfinancial risks can be handled in a better way.

In addition to helping to better describe (financial) decision problems, financial theory provides a number of crucial insights. The most obvious (and surely not limited to financial economics) is probably the concept of "best alternative opportunity" thinking. Whenever making an evaluation of decision alternatives, one should take into account that the decision maker may have alternative opportunities (often but not exclusively provided by markets), the best of which sets a benchmark for the evaluation of the decision alternatives considered.

Other concepts are the efficient market hypothesis and the no-arbitrage condition. These point both to the fact that in competitive environments, it is not obvious that one can outsmart all the others. So if you find ways to make easy money, you should at least try to answer the question why you are the lucky one and how the environment will react.

\section{Describing uncertainty and risk using multi-dimensional profiles ${ }^{3}$}

The effects of financial decisions are distributed over future time periods and are uncertain. In order to evaluate these possible effects, available information should be used to develop a 'picture' of these effects and their likelihood. In our framework, two questions play a crucial role:

- Where does the uncertainty stem from or, in other words, what are the sources of risk?

- When and how can this uncertainty be changed?

The answer to the first question leads to the decomposition of uncertainty. This involves attributing the inherent risk (the potential variability in the outcomes) to the variability in several underlying state variables or factors. We can thus view the outcomes as being generated by the factors. Conversely, the stochastic outcomes are conditioned on these factors. The degree in which fluctuations in the factors propagate into fluctuations in the outcomes can be measured by response coefficients. These sensitivity coefficients can then be interpreted as exposures to the underlying risk factors and together they constitute the multi-dimensional risk profile of a decision alternative.

\footnotetext{
${ }^{3}$ This section draws heavily on a part of Hallerbach \& Spronk [2000].
} 
The answer to the second question leads to three prototypes of decision problems:

A. The decision maker makes and implements a final decision and waits for its outcome. This outcome will depend on the evolution of external factors, beyond the decision maker's control.

B. The decision maker makes and implements a decision and observes the evolution of external factors (which are still beyond the decision maker's control). However, depending on the value of these factors, the decision maker may make and implement additional decisions. For example, a decision maker may decide to produce some amount of 'a new and spectacular software package' and then, depending on the development of the market, he may decide to stop, decrease or increase production.

C. As in B, but the decision maker is not the sole player and thus has to take account of the potential impact of decisions made by others sometime in the future (where the other(s) are of course confronted with a similar type of decision problem). The interaction between the various players in the field gives rise to dynamic game situations.

\section{Multi-dimensional risk profiles in "prototype A" problems}

The complexity of the decision process stems from assessing probability information regarding the outcomes (the "information problem") and from confronting this probability information with the preference structure of the decision maker (or incorporating it in some preference functional, the "criterion problem"). In general, the process of conditioning and decomposition greatly reduces the complexity of the decision process. ${ }^{4}$ With respect to the information problem, decomposition reduces the complexity of risk judgments because it allows shifting attention from the onedimensional probability distribution of the outcomes to the exposures to the underlying factors, summarized in the risk profile. ${ }^{5}$ In this setting, the decision maker is relieved of the burden to specify the probability distribution of the outcomes. Moreover, it is not even necessary that he has detailed information regarding the distributions of the factors. When a decision alternative shows a larger sensitivity (in absolute sense) to some factor $j$, it has a larger exposure to factor $j$ risk, meaning that potential fluctuations in that factor propagate to a larger extent into potential fluctuations of the outcomes. So when two decision alternatives have the same risk profile except for the exposure to factor $j$, the alternative with the smaller exposure is less risky. This brings us to the criterion problem. Instead of the need to incorporate either the whole probability distribution of the outcomes or its relevant moments in the decision process, it suffices to express preferences with respect to the risk profile as summarized by the factor exposures. These sensitivity coefficients thus become the relevant risk attributes of the decision alternatives.

A multidimensional view on risk allows multidimensional attitudes towards risk. A decision maker can show different degrees of aversion towards variability in the outcomes depending on the specific type of the underlying risk generating factor. Aside from the type of risk source, also the size of the exposure matters. A small exposure combined with large factor variability can generate the same degree of risk

\footnotetext{
${ }^{4}$ The general idea of decomposition for the resolution or reduction of uncertainty can be traced to Simon [1962]. The process of conditioning described here is in the spirit of the stochastic hierarchies of Raiffa [1968].

${ }^{5}$ In effect, combining the conditional distributions of the outcomes with respect to the factors with the marginal (joint) distributions of the factors yields the unconditional distribution of the outcomes. Ravinder, Kleinmuntz \& Dyer [1988] analyse the measurement error that can be attributed to the use of decomposition when compared to direct assessment.
} 
as a large exposure combined with small factor variability. However, the decision maker can face restrictions on risk exposures or possess smaller or larger buffers to absorb different types of risks. An example of the former is a restriction placed by a firm on the currency risk attached to its sales abroad; an example of the latter is the stock of input resources a firm holds in order to maintain production continuity.

Risk and variability are by no means synonymous. In general, there is a clear dichotomy between downside variability and upside variability. When a decision maker strives to maximize an alternative's outcome, downside risk can be separated from upside potential. When a decision maker instead strives to minimize the outcome, the asymmetry is reversed. This observation not only holds in general for the potential variability in the outcomes, but also more specifically for the potential fluctuations of the factors. Not only restrictions on risk exposures play a role, or the presence of buffers to absorb the unwanted part of variability, but also the availability of specific instruments that can be used to mitigate or eliminate the exposure to some part of factor variability. This leads us to the issue of risk management and the application of derivative instruments, as discussed below.

A multidimensional view on risk quite naturally allows for performing sensitivity analyses. Given the factor exposures, it can be analysed how the outcomes are influenced by various changes of the factor values. Likewise, the decision maker can determine how the outcomes are influenced by hypothesized changes in the exposures to the factors. This implies a dynamic instead of a static approach to problem solving. The decision maker can $(i)$ evaluate the different risk profiles that are generated by the set of available alternatives; by examining the trade-offs offered by the alternatives he can (ii) obtain new insights and shape his preferences in more detail, or (iii) realize that he needs more information on a specific part of the problem. Because of this interdependence between the characteristics of the choice alternatives and the decision maker's preferences, the aspect of learning in a complex decision situation gains importance. This leads us to situations where the decision maker may make additional decisions, depending on the course of the environment.

\section{The use of contingent claims in "prototype B" problems}

In a capital budgeting context, an investment project derives its present value from the future cash flows it generates. The project's cash flows -and hence its value- can be conditioned on factors describing its economic context, like commodity prices, exchange rates, interest rates and inflation. The vector of its exposures for these factors constitutes the project's characterizing risk profile. This multi-dimensional representation enriches the project's description and enhances its evaluation. This applies even when information about the type and nature of risk sources or about the exposures is incomplete. By pasting as many pieces of the puzzle as possible together, one can obtain an impression of the weak and strong sides of the project, especially when comparing it to other competing projects.

When evaluating a portfolio of investment projects, also the diversification effect is relevant. Not the sum of the risks attached to the separate projects is relevant, but the risks attached to the sum of the projects. The lower the degree of dependence between the underlying risks, the greater the benefits reaped from the diversification effect. Aside from diversification, a firm may control risks by matching factor exposures. Combining a project with an exposure to factor $j$ of +1 with a project with an exposure of -1 will in effect eliminate the exposure to factor $j$ risk. 
When evaluating risk profiles of decision alternatives both the trade-offs between the various risk exposures and the trade-off between risk and return are relevant. This risk-return trade-off implies that there is a reward for bearing risks. For example, lowering a project's risk exposures can at the same time decrease its value or profitability. A firm must then compare the risk-return trade-off offered by the portfolio of investment opportunities to the risk-return trade-off implied by its degree of risk aversion. So, generally speaking, there is a reward for risk offered by the decision alternatives, and there is premium for risk required by the decision maker - the subjective price of risk. To complicate things in a necessary way, there is in addition a reward for risk offered and required by the "outside world". When this socalled market price of risk exceeds the subjective price of risk, the firm clearly has a comparative advantage - i.e., compared to the outside world - in bearing the risk. The firm then has specific and valuable expertise in handling the risk in the decision context at hand.

Above, we already mentioned the possibilities of diversification and matching in order to change risk profiles. But what opportunities does a firm have to sell risks to third parties? This question opens a whole toolbox of financial instruments, designed for hedging purposes. These derivative instruments or "contingent claims" are used to transfer risk exposures from parties that do not want or are not able to bear these risks, to parties who are better equipped to handle them. Option contracts, forward contracts, futures, and swaps are some examples of derivatives that allow a firm to hedge, i.e. to adjust individual risk exposures by shifting them to others. ${ }^{6}$ Option contracts take a special position, since they work in an asymmetric way, like insurance contracts: they allow selling the downside risk of an exposure (by paying a market price) while maintaining its full upside potential. By choosing the right kind of contingent claims contract, risk exposures can be eliminated with surgical precision - provided the decision maker has sufficient knowledge of the nature of the contracts involved. With the increasing complexity of the available contracts, a detailed and sophisticated contingent claims analysis is a prerequisite to successful risk management.

Contingent claims analysis not only focuses on explicit options (i.e. the options that are traded on financial markets) but also on implicit options. The latter options are embedded in decision alternatives and manifest themselves as "flexibility". For example, during the life of an investment project the firm may expand the project when profitable or abandon it when it proves disappointing. A firm may even have the option to postpone the decision and start a project when and if market conditions prove favourable. ${ }^{7}$

The above discussion urges us to expand the description of decision alternatives. Of course, the exposures to the underlying sources of risks are still an essential part of a risk profile. To this, we have to add the aspects of flexibility, relating to the possibility to make decisions at some point in the future depending on the evolution of the environment.

\section{Contingent claims and games in "prototype C" problems}

The decision maker is of course not the sole player in this environment. This implies that the potential impact of decisions taken by others sometime in the future must also be taken into account. The interaction between the various players in the field gives

\footnotetext{
${ }^{6}$ Smithson [1998] provide a good introduction to financial risk management and the use of derivatives for hedging; on the latter, see also Hull [2003].

${ }^{7}$ For an overview, see for example Brealey \& Myers [2003].
} 
rise to game situations. For example, suppose we have two competitors, firm A and firm B. Firm A expects B to enter the market and is trying to understand B's likely pricing strategy. Firm A can then construct a payoff matrix, summarizing the payoffs (sales or net profit, e.g.) under various pricing strategies. Firms A and B have perverse incentives to lower prices: maintaining prices at the current level while the competitor cuts prices will lower the payoff. Like in the prisoner's dilemma, both firms are inclined to cut prices, thus both lowering their payoff. As a result, we can imagine that each firm then will separately try to compete on other factors, like product features, service levels or advertising. An analysis of this pricing game can only be made when the firm has information about costs to enter and exit the market, about demand functions, about revenue, cost structures etc. So the decision process has various dynamic aspects, stemming on the one hand from flexibility in the own decision context and on the other hand from the impact of other parties' decisions on this decision context. Because of these dynamic aspects, the role of learning - from your own decisions and from others - cannot be underestimated.

\section{Conclusions}

Most financial decisions are made consciously, with a clear and constant drive to make "good", "better" or even "optimal" decisions. In this drive to improve on financial decisions, we stumble across an area of tension between decision making in practice on the one hand and the potential contributions of finance theory and decision tools on the other. Although the bulk of finance theory is of a descriptive nature, focusing on the "average" or "representative" decision maker, we observe a large willingness to apply financial theory in actual, "non-average" decision-making. Clearly there is need of a framework that can provide guidance in using financial theory, decision tools and common sense to solving financial problems. Over the last fifty years or so, financial theory has produced very powerful results. Although much of the theory has been developed for the "average" case, many of the insights and of the descriptive tools (including their descriptive language) can -and sometimes should- be used in "non-average" cases. Non-average financial decision problems are often not pure but instead mixed financial problems, i.e. problems in which other considerations than financial considerations play their role (cf. section 5). This gives rise to the need to describe the decision alternatives in terms of multi-dimensional impact profiles. In all financial problems, pure and mixed, the available information is not complete. We show multi-dimensional risk profiles are useful tools in capturing incomplete information (cf. section 6). These profiles lead to a multi-dimensional framework that can support the financial-economic decision making process, while benefiting from the insights financial theory has to offer. 


\section{References}

Ashford, R.W., R.H. Berry \& R.G. Dyson, 1988, "Operational Research and Financial Management", European Journal of Operational Research 36, pp. 143-152

Black, F. \& M. Scholes, 1973, "The Pricing of Options and Corporate Liabilities", The Journal of Political Economy 81/3, May/June, pp. 637-659

Bodie, Z. \& R. C. Merton, "Finance", Prentice Hall, 2000

Bollerslev, T., 2001, "Financial Econometrics: Past Developments and Future Challenges", Journal of Econometrics 100, pp.41-51

Brealey, R.A. \& S.C. Myers, 2003, "Principles of Corporate Finance”, $7^{\text {th }}$ Edition, McGraw-Hill, New York

Derman, E., 1996a, "Valuing Models and Modelling Value", The Journal of Portfolio Management, Spring, pp.106-114

Derman, E., 1996b, "Model Risk", RISK 9/5, May, pp.34-37

Elton, E.J. \& M.J. Gruber, 1997, "Modern Portfolio Theory, 1950 to date", Journal of Banking \& Finance 21, pp.1743-1759

Fama, E.F. \& M.H. Miller, 1972, “The Theory of Finance”, Dryden Press, Hinsdale Ill.

Hallerbach, W.G. \& J. Spronk, 2000, “A Multicriteria Framework for Risk Analysis", in: Y.Y. Haimes \& R. Steuer (eds), Research and Practice in Multiple Criteria Decision Making, Lecture Notes in Economics and Mathematical Systems, Vol. 487, Springer Verlag, Berlin, pp. 272-283

Hallerbach, W.G. \& J. Spronk, 2002, "Why MCDM in Finance: The Relevance of Multi-Criteria Decision Making for Financial Decisions", to appear in The Journal of Multicriteria Decision Analysis, available as ERIM report ERS-200269-F\&A, http://www.eur.nl/WebDOC/doc/erim/erimrs20020909173443.pdf

Hastie, K.L., 1982, “A Perspective on Management Education”, Financial Management 11/4, Winter, pp. 55-62

Hull, J.C., 2003, “Options, Futures and Other Derivatives”, Prentice-Hall, Upper Saddle River NJ

Jarrow, R.A., 1988, "Finance Theory”, Prentice-Hall, Englewood Cliffs, NJ

Jorion, Ph., 2001, "Value at Risk: The Benchmark for Controlling Market Risk”, McGraw-Hill, Chicago Ill.

Keynes, J.N., 1891, “The Scope and Method of Political Economy”, Macmillan, London

McInnes, J.M. \& W.J. Carleton, 1982, "Theory, Models and Implementation in Financial Management”, Management Science 28/9, pp. 957-978

Markowitz, H.M., 1950, “Theories of Uncertainty and Financial Behavior" (abstract), Econometrica 19 (Chicago Meeting Report), pp 325-326

Markowitz, H.M., 1952, "Portfolio Selection", Journal of Finance, March pp 77-91

Martel J.M. \& C. Zopounidis, 1998, "Critères multiples et décisions financiers", Revue FINECO 8, pp.1-12

Merton, R.C., 1973, "Theory of Rational Option Pricing", Bell Journal of Economics 4, Spring, pp. 141-183

Merton, R.C., 1995, "Influence of mathematical Models in Finance on Practice: past, Present, and Future", Financial Practice and Education 5/1, Spring/Summer, pp.7-15

Raiffa, H., 1968, “Decision Analysis”, Addison-Wesley, Reading 
Ravinder, H.V., D.N. Kleinmuntz \& J.S. Dyer, 1988, “The Reliability of Subjective Probabilities Obtained Through Decomposition", Management Science 34, pp.186199.

Ross, S.A., 1989, "Finance”, in: J. Eatwell, M. Milgate \& P. Newman (eds), "The New Palgrave Finance”, MacMillan, Hong Kong, pp. 1-34

Simon, H.A., 1962, "The Architecture of Complexity", Proceedings of the American Philosophical Society 106, 467-482

Smithson, C.W., 1998, "Managing Financial Risk”, Irwin, Burr Ridge

Spronk, J. \& W.G. Hallerbach, 1997, "Financial Modelling: Where to Go? With an Illustration for Portfolio Management”, European Journal of Operational Research 99, pp.113-125

Spronk, J. \& E.M. Vermeulen, 2003, Comparative performance evaluation under uncertainity, European Journal of Operational Research, forthcoming

Steuer R.E. \& P. Na, 2002, "Multiple Criteria Decision Making Combined with Finance: A Categorized Bibliography", Special Issue on Financial Modelling, European Journal of Operational Research, forthcoming

Zopounidis, C., 1999, "Multicriteria Decision Aid in Financial Management", European Journal of Operational Research 119, pp. 404-415 


\section{Publications in the Report Series Research* in Management}

ERIM Research Program: "Finance and Accounting"

2003

COMMENT, Risk Aversion and Skewness Preference Thierry Post and Pim van Vliet ERS-2003-009-F\&A

International Portfolio Choice: A Spanning Approach

Ben Tims, Ronald Mahieu

ERS-2003-011-F\&A

Portfolio Return Characteristics Of Different Industries Igor Pouchkarev, Jaap Spronk, Pim van Vliet ERS-2003-014-F\&A

Statistical Inference on Stochastic Dominance Efficiency.

Do Omitted Risk Factors Explain the Size and Book-to-Market Effects?

Thierry Post

ERS-2003-017-F\&A

A Multidimensional Framework for Financial-Economic Decisions

Winfried Hallerbach \& Jaap Spronk

ERS-2003-021-F\&A

A Range-Based Multivariate Model for Exchange Rate Volatility

Ben Tims, Ronald Mahieu

ERS-2003-022-F\&A

Macro factors and the Term Structure of Interest Rates

Hans Dewachter and Marco Lyrio

ERS-2003-037-F\&A

\footnotetext{
A complete overview of the ERIM Report Series Research in Management: $\underline{\text { http://www.erim.eur.nl }}$

ERIM Research Programs:

LIS Business Processes, Logistics and Information Systems

ORG Organizing for Performance

MKT Marketing

F\&A Finance and Accounting

STR Strategy and Entrepreneurship
} 